\title{
A Study on the Cytotoxicity of plectranthus amboinicus and bacopa monnieri stem Extracts on Lung Cancer Cell Line
}

\author{
Anixa Zara George, Kaveri Anil, Calistus Jude A.L.* and Srinivasan, Srinivasa Sundar Rajan R \\ Department of Life Sciences, Kristu Jayanti College, Autonomous, Bengaluru - 567 077, Karnataka, India
}

*Corresponding author: cjude@kristujayanti.com

\begin{abstract}
Cancer is one of the leading causes of morbidity and mortality. Many treatment modalities have been developed and the need for plant derived therapeutic is growing due to the adverse effects of chemotherapeutic agents. The present study aims to discover the potential of two herbs Plectranthus amboinicus and Bacopa monnieri. Screening for the bioactives in the methanolic extracts of Plectranthus amboinicus and Bacopa monnieri stem showed the presence of alkaloids, flavonoids, terpenoids, phenols, saponins, carbohydrates. A comparative study on the cytotoxicity of methanolic extracts of the stem of these plants on lung epithelial cancer cell line A549 and normal fibroblast cell line L929 revealed that both extracts possess cancer cell specific cytotoxic activity. However, Bacopa monnieri stem extracts were found to be more effective in inducing cytotoxicity than Plectranthus amboinicus.
\end{abstract}

Keywords Plectranthus amboinicus; Bacopa monnieri; A549; Cytotoxicity

\section{Introduction}

Cancer remains to be the second leading cause of death in both developed and developing countries. The development of modern drug targeted therapies has beyond doubt improved care for cancer patients. However, many cancers in advanced stages remain untreatable. Hence the continued search for safer and more effective therapeutics is needed at a comparative cost for cancer care. Use of natural phytochemical compounds is becoming a more acceptable strategy to prevent, impede, delay, or cure cancer. A majority of plantderived phytoconstituents, such as paclitaxel, etoposide, camptothecin, vinca alkaloids, indole alkaloids, podophyllotoxin derivatives, etoposide and teniposide are currently used in clinical cancer. Natural products from plants with medicinal properties are a source of new drugs. In the current study, two famed herbs Plectranthus amboinicus and Bacopa monnieri were chosen and their potential as cytotoxic and cytoprotective agents were analyzed in the stem extracts. Plectranthus amboinicus (Lour) Spreng, is commonly known as country borage. It is a folkloric medicinal plant used to treat malarial fever, hepatopathy, renal and vesicle calculi, cough, chronic asthma, intense cough, bronchitis, colic convulsions and epilepsy (1). The leaves exhibit significant antioxidant potency, reducing power, superoxide anion radical scavenging ability, nitric oxide radical scavenging, and ferrous ion chelating ability (2). They contain essential oils, flavonoids and terpenes which possess inhibitory effect against Gram-positive and Gram-negative bacteria (3). Antimutagenic, antitumorogenic, and antigenotoxic effects of Indian borage leaves have also been documented $(4,5)$.

Bacopa monnieri (common name: Brahmi) is well known in ayurvedic medicine to have antioxidant properties. It has been used for centuries to help benefit epilepsy, memory and reduce stress-induced anxiety. It is a bitter, pungent, heating, emetic, laxative useful in ulcers, tumors, ascites and enlargement of spleen, indigestion, inflammations, leprosy, anemia and biliousness. The presence of bacoside A and B in BM leaves attributes to their neurobeneficial function (10), antiamnesic (11), antioxidant (12), anxiolytic (13) and antiulcerogenic activities (14). Recent studies suggest that Bacopa monnieri also exerts anti-inflammatory (15) and antiarthritis activity (16).

Although, there is surplus of information on $P$. amboinicus leaves and $B$. monnieri leaves to our knowledge, no much information is available about its stem. In this background, the present investigation was carried out to determine phytochemical composition of $P$. amboinicus stem and $B$. monnieri stem to evaluate its antioxidant potential and cytotoxicity on human lung cancer cell lines.

\section{Materials and Methods}

Stems of Bacopa monnieri were collected from East Kadungalloor, Kerala. Plectranthus ambionicus was collected from, Horamavu, Bangalore, Karnataka. Plant collection was done during the month of December. The collected plant parts were further surface sterilized by washing and were shade dried for two weeks.

The stem of the plants was chopped into fine pieces. Soxhlet extraction was carried out separately for both plants using $50 \mathrm{~g}$ of the dried stems in $500 \mathrm{ml}$ of methanol as the solvent. The extraction was carried out at $67^{\circ} \mathrm{C}$ and the filtrate was concentrated in a rotary evaporator under reduced pressure to yield dry extracts. The methanolic extracts of the stems of Plectranthus ambionicus (PSM) and Bacopa monnieri (BSM) were stored at $4^{\circ} \mathrm{C}$ until use.

Preliminary investigations to identify the phytochemical compounds in the methanolic stem extracts of both plants were performed. The antioxidant activity of the extracts was estimated by Ferric Reducing Antioxidant Power (FRAP) 
assay. Working standard ascorbic acid was prepared and pipetted out into 5 standards (s1, s2, s3, s4, s5: 0.2, $0.4,0.6,0.8,1)$. Two tests $\mathrm{t} 1$ and $\mathrm{t} 2$ were taken (BSM and PSM). $3.8 \mathrm{ml}$ FRAP reagent was added to all tubes. It was incubated in the water bath for 30 minutes and the O.D value was taken at $570 \mathrm{~nm}$ against reagent blank (FRAP reagent $+1 \mathrm{ml}$ distilled water)

The chemical compounds and functional groups present in the extracts were identified using Fourier Transform Infrared Spectroscopy (FTIR). The wavelength of light absorbed is characteristic of the chemical bond as can be seen in the annotated spectrum. By interpreting the infrared absorption spectrum, the chemical bonds in a molecule can be determined.

MTT assay is a colorimetric assay used for the determination of cell proliferation and cytotoxicity, based on reduction of the yellow-colored water-soluble tetrazolium dye MTT to formazan crystals which upon dissolution into an appropriate solvent exhibits purple color, the intensity of which is proportional to the number of viable cells and can be measured spectrophotometrically at $570 \mathrm{~nm}$. In the present study, this assay was performed to determine the cytotoxic potential of the extracts. The A549 (Human lung adenocarcinoma cell line) and L929 (Mouse fibroblast cell line) were exposed to five different concentrations of the extract $(25,50,100,200,400 \mu \mathrm{g})$ and the percent cell viability was estimated. The vehicle used was DMSO.

\section{Results and Discussion}

The importance of plants in the field of medicine is increasing day by day due to their safety and reduced toxicity. This study was aimed to assess the cytotoxic potential of two medicinal plants, Plectranthus ambionicus and Bacopa monnieri against human lung cancer (A549) cell lines and cytoprotective effect on a normal cell line (L929). In plants the naturally occurring chemical compounds are phytochemicals. They give organoleptic properties and color to the plant. Medicinal plants contain phenols, flavonoids, saponins, and many other phytochemicals that exert multiple biological effects including antioxidant and free radical scavenging, anti-inflammatory, anti-proliferative activities, and others. Some phytochemicals are known to reveal medicinal and physiological activities which are phenols, tannins, flavonoids, saponins, carbohydrates, alkaloids, phytosterols, etc. Literature survey revealed the occurrence 76 volatiles and 30 nonvolatile compounds belonging to different classes of phytochemicals such as monoterpenoids, diterpenoids, triterpenoids, sesquiterpenoids, phenolics, flavonoids, esters, alcohols and aldehydes in leaf extracts. The leaf essential oil of $P$. amboinicus is particularly rich in phenolic monoterpenes such as Thymol and Carvacrol, which are speculated to exert various pharmacological properties (6). Phytochemical screening of the extract of Plectranthus ambionicus stem revealed that it contained good amounts of total phenolics, flavonoids and proanthocyanidins. Plant polyphenols (flavonoids, flavonols, proanthocyanidins, phenolic acids, etc.) have been associated with antioxidant, antibacterial, anticancerous and antiplatelet activities. Studies for the identification of bioactive molecules in the extract by HPLC showed the presence of some known antioxidant molecules, namely, rosmarinic acid, caffeic acid, rutin, gallic acid, quercetin, and $p$-coumaric acid in dried extracts (4).

B.monnieri contained alkaloid brahmine, nicotinine, herpestine, bacosides $A$ and $B$, saponins $A, B$ and $C$, triterpenoid saponins, stigmastanol, $\beta$-sitosterol, betulinic acid, D-mannitol, stigmasterol, $\beta$-alanine, aspartic acid, glutamic acid, and serine and pseudojujubogenin glycoside (17). B.monnieri methanol extract showed the presence of flavonoids, saponins, carbohydrates, tannins, oils and fats. Aqueous extract contained flavanoids, saponins and carbohydrates. Petroleum ether and chloroform extract showed negative result for all the compounds (18). The phytochemical analysis in the present study on the extracts revealed the presence of alkaloids carbohydrates, glycosides, phenol and tanins, phytosterols and saponins in both extracts. The concentration of many of these were higher in PSM when compared to BSM.

The FTIR spectrum was used to identify the functional groups of the probable bioactive components based on the peak value in the region of infrared radiation. The results of the analysis on PSM showed absorbance at $3696.40 \mathrm{~cm}^{-1}$ which may be formed due to the broad stretching of the hydroxyl group. The peak at $3434.43 \mathrm{~cm}^{-1}$ was due to the stretching of primary amines. At $2942.78 \mathrm{~cm}^{-1}$ the peak was due to the presence of alkanes. At the peak at $2383.46 \mathrm{~cm}^{-1}$, the band was due to $\mathrm{N}=\mathrm{C}$ stretching. At $2280.88 \mathrm{~cm}^{-1}$ the band was due to $\mathrm{N}-\mathrm{H}$ stretching. The peak at $1659.89 \mathrm{~cm}^{-1}$ and $1588.27 \mathrm{~cm}^{-1}$ were due to $\mathrm{C}=\mathrm{C}$ bonding. The peak at $1527.85 \mathrm{~cm}^{-1}$ was due to the presence of a nitro group. At $1469.9 \mathrm{~cm}^{-1}$ and $1425.48 \mathrm{~cm}^{-1}$, the band formed was due to $\mathrm{C}-\mathrm{H}$ stretching. The peak formed at $1065.94 \mathrm{~cm}^{-1}$ was due to the $\mathrm{C}-\mathrm{O}$ stretching. At $823.54 \mathrm{~cm}^{-1}$ the band was formed due to $\mathrm{C}=\mathrm{C}$ bonding. The peak formed at $628.62 \mathrm{~cm}^{-1}$ was due to the presence of halo compounds (Fig. 1 and Table 1).

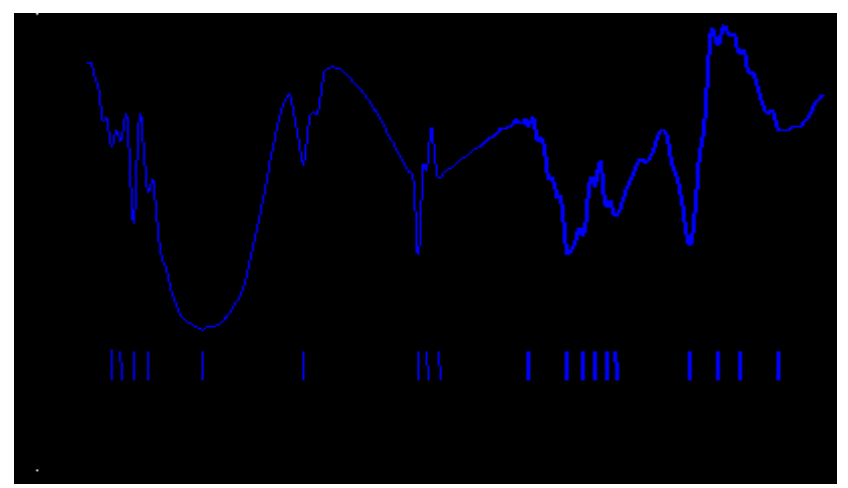

Fig.1. FTIR spectrum of PSM

Fig. 2 and Table 1 depict the results of FTIR analysis of BSM. The absorbance at $3413.52 \mathrm{~cm}^{-1}$ was due to 
Table 1. FTIR spectral peak values and functional groups on analysis of PSM

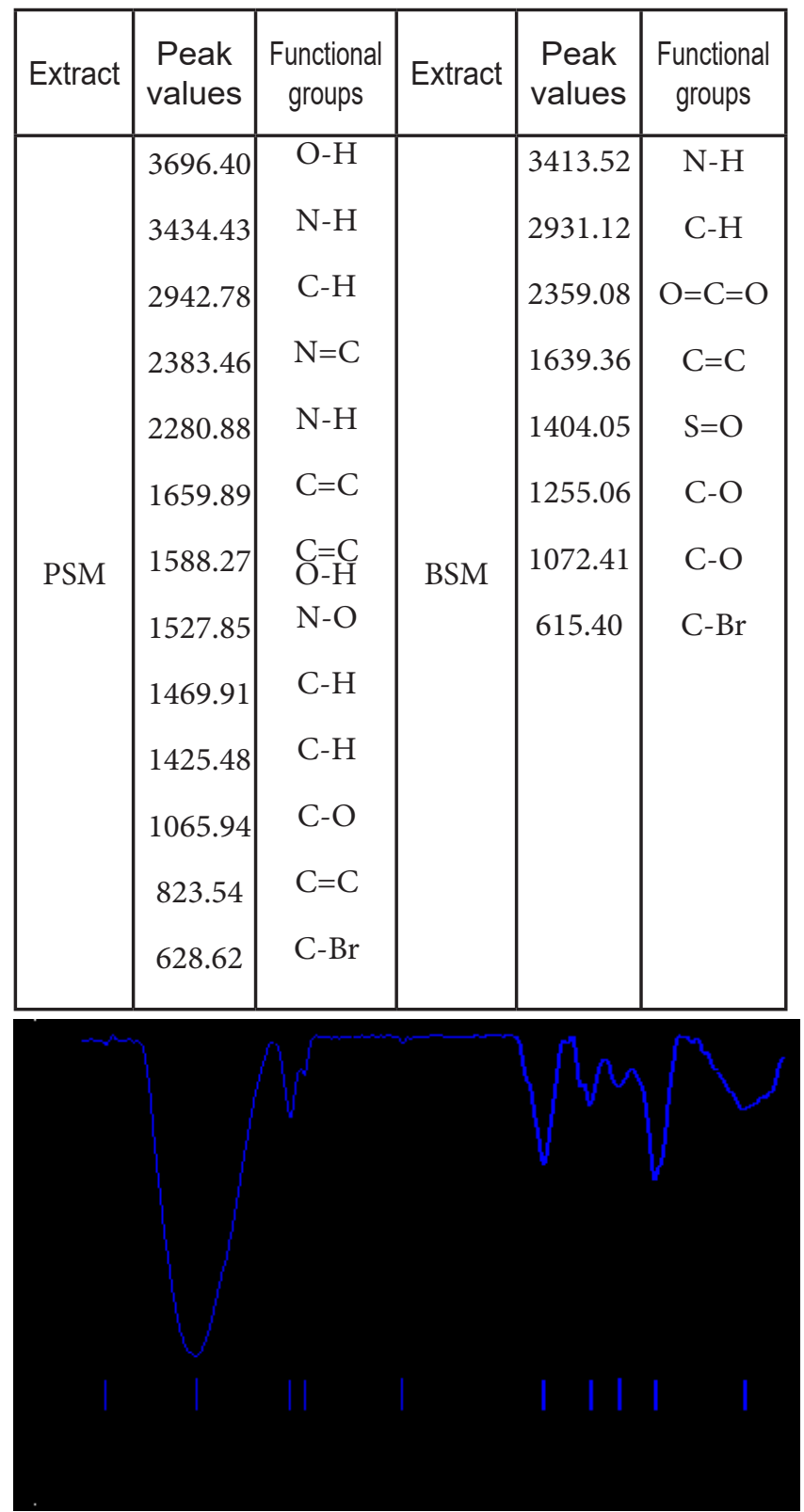

Fig.2. FTIR spectrum BSM

Table 2. Radical Scavenging effect of PSM and BSM

\begin{tabular}{|c|c|c|}
\hline Test sample & Concentration $(\mu \mathrm{g})$ & $\begin{array}{c}\text { Radical Scavenging } \\
(\%)\end{array}$ \\
\hline PSM(T1) & 27 & 71.69 \\
\hline BSM(T2) & 41 & 52.66 \\
\hline
\end{tabular}

the stretching of primary amines and at $2931.12 \mathrm{~cm}^{-1}$ was due to the $\mathrm{C}-\mathrm{H}$ symmetric stretching vibrations. At $2359.08 \mathrm{~cm}^{-1}$ the band was formed due to the $\mathrm{O}=\mathrm{C}=\mathrm{O}$ stretching. Band formed at $1639.36 \mathrm{~cm}^{-1}$ was due to the stretching of alkenes and the band at $1404.05 \mathrm{~cm}^{-1}$ was due to the asymmetrical SO2 stretching vibration. At $1255.06 \mathrm{~cm}^{-1}$ and $1072.41 \mathrm{~cm}^{-1}$ the band was formed due to the stretching of alkyl aryl ethers and the band formed at $615.40 \mathrm{~cm}^{-1}$ was due to the presence of the stretching of halo compounds in the extract.

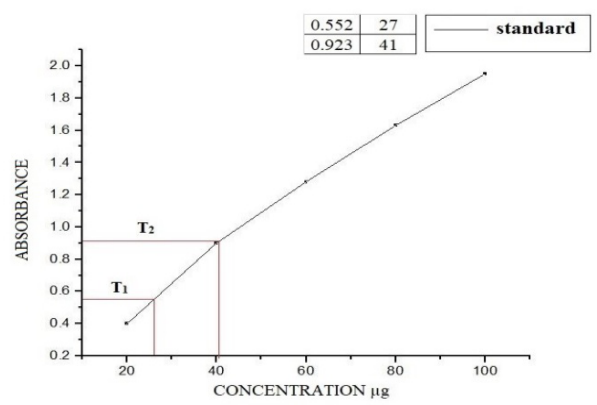

Fig.3.The free radical Scavenging activity of PSM and BSM

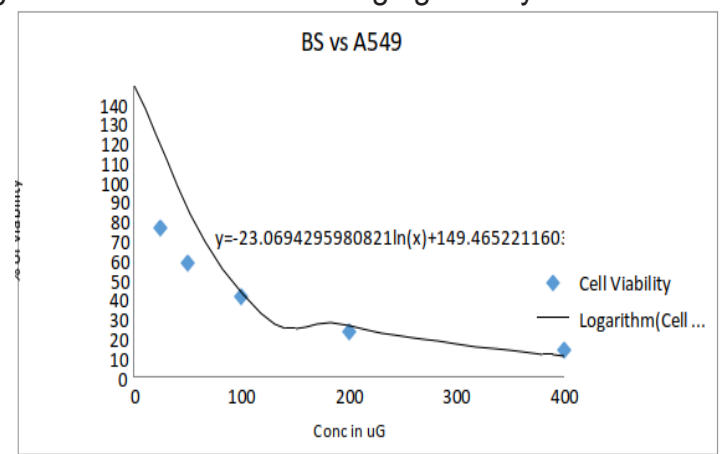

Fig 4.1: Cytotoxicity of different concentrations of BSM on A549 cell line

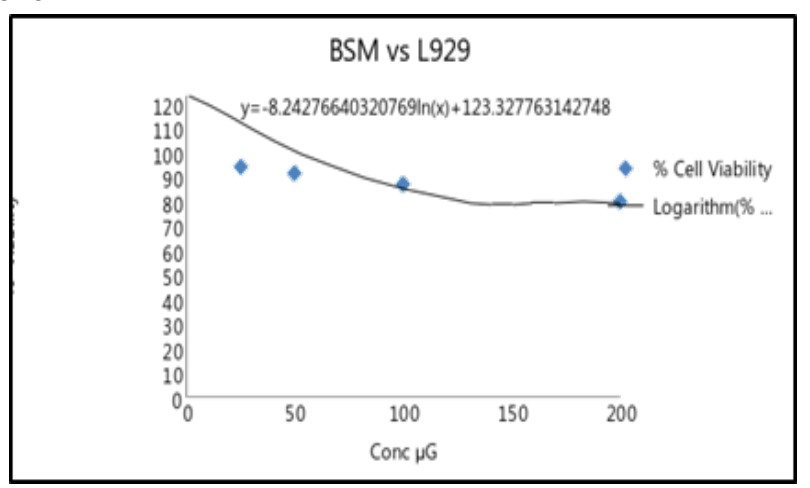

Fig.4.2: Cytotoxicity of different concentrations of BSM on L929 cell line

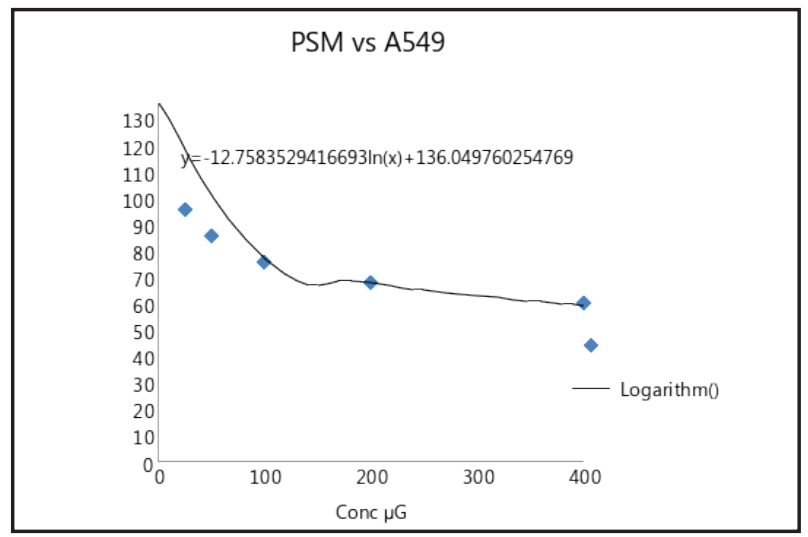

Fig 5.1: Cytotoxicity of different concentrations of PSM on A549 cell line

Antioxidants are substances that can prevent or reduce damage to cells caused by free radicals which are unstable molecules that the body produces as a reaction to environmental and other pressures. Antioxidants play an important role in reducing the stress on cells in chronic diseases like cancer. Antioxidants play a major role in 
deciding the pharmaceutical effect of plants and making them potent drugs against chronic diseases. Previous study on borage leaves (4) on the total antioxidant capacity of methanolic extract of leaves was found to be $782.56 \mathrm{BM} \mathrm{AAE} / \mathrm{g}$ of extract. The superoxide anion radical scavenging activity of the methanol extract of $P$. amboinicus stem was dose dependant and increased significantly $(\beta \leq 0.05)$ with increase in concentration. An appreciable scavenging activity was observed $(61 \%)$ at $250 \mathrm{ppm}$ indicating that the extract contains antioxidants that can scavenge superoxide anions The stem extract showed a total antioxidant capacity of $634.95 \mathrm{M} \mathrm{AAE} / \mathrm{g}$ of extract (7).

The extract of Bacopa monnieri showed IC 50 value of aqueous extract to be a higher DPPH radical activity than methanol, chloroform and petroleum ether extracts. Total antioxidant assay the ammonium molybdate method had been used and aqueous extract showed higher antioxidant activity compared to methanol. The aqueous extract showed more reducing power activity than the methanol extract (18).

The total antioxidant capacity of plant extracts varies, depending on the type and content of phenolics.

The FRAP assay performed on the plant extracts in the current study shows that PSM and BSM may have a high amount of antioxidant which was comparable to that of the synthetic antioxidant standard used (Table 2 and Fig. 3). In the current study, P. amboinicus extract (PSM) showed higher percentage of scavenging activity $(71.69 \%)$ when compared to B.monnieri $(52.66 \%)$ which could be due to the increased concentration of phytochemicals in P.amboinicus.

The MTT assay is a widely-used test to evaluate the metabolic activity of cultured cells by measuring the activity of the mitochondrial succinate dehydrogenase enzyme. This test evaluates the in vitro cytotoxic and cytostatic activities of medicinal plant extracts. In the present study, Human Lung Adenocarcinoma Cell Line (A549) and Mouse Normal Fibroblast Cell Line (L929) were exposed to increasing concentrations (25 to 600 $\mu \mathrm{g} / \mathrm{ml}$ of culture medium) of PSM and BSM for a period of 24 hours.

The methanolic extract of Plectranthus ambionicusstem (PSM) was tested for its cytotoxicity on the A549 cell line. Fig.5.1 depicts the percent cytotoxicity of PSM against A549 cell line. At $25 \mu \mathrm{g}$ concentration, the cell viability was $95.84 \%$. As the concentrations were increased to $200 \mu \mathrm{g}$ and $400 \mu \mathrm{g}$, the percentage of viable cells recorded were 68.03 and 60.67 respectively. The IC50 value of PSM extract was calculated to be 872.75 and this denotes that there is no significant cytotoxicity exhibited by the extract.

Fig 5.2.depicts the effect of PSM on the normal cell line L929. The viability of the cells, even at a concentration of $200 \mu \mathrm{g}$,was found to be $80 \%$. This shows that there is only mild toxicity even at a high concentration of PSM extract on normal fibroblast cells. As there is only a $20 \%$ reduction in the number of viable cells, the IC50 value was not applicable.

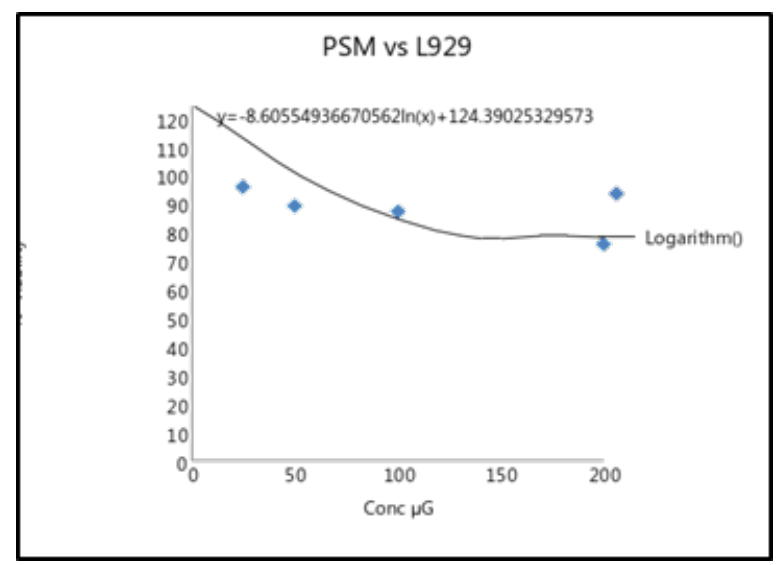

Fig 5.2. Cytotoxicity of different concentrations of PSM on L929 cell line

The antitumor activity of hydroalcoholic extracts of $P$. amboinicus has been reported, the results showed a significant inhibition on the growth of Sarcoma-180 tumor in mice treated with the hydroalcoholic extracts of $P$. amboinicus. (8). The $P$. amboinicus ethanolic extract showed significant anticancer activity through inducing apoptosis in the A549 (human lung cancer) cell line (9). The stem extract was found to have the strongest cytotoxic effect against HCT-15 with $73.58 \%$ cell viability inhibition at 1000 ppm, followed by MCF-7 (55.17\%) at the same concentration, cytotoxic effect was least for Caco-2 cell line with a cell inhibition of $34.13 \%$ at 1000 $\mathrm{ppm}$. The IC50 values against the cell lines were 650, 995, and 2090 ppm for HCT-15, MCF-7, and Caco-2, respectively (7).

Fig 4.1. Depicts the percent cytotoxicity of BSM on A549 cell line in the present study. At $25 \mu \mathrm{g} / \mathrm{ml}$ concentration, the viability of the cancer cells was $76.74 \%$. The cell viability was reduced exponentially as the concentration of extract increased and at $400 \mu \mathrm{g}$ concentration, only $14 \%$ of the cells were viable. The IC50 value of BSM was calculated to be $75.31 \mu \mathrm{g} / \mathrm{ml}$.

Fig 4.2. depicts the effect of BSM on normal mouse fibroblast cell line. At $25 \mu \mathrm{g}$ concentration, the cell viability was $94.71 \%$ and as the BSM concentration was increased there was no significant reduction in

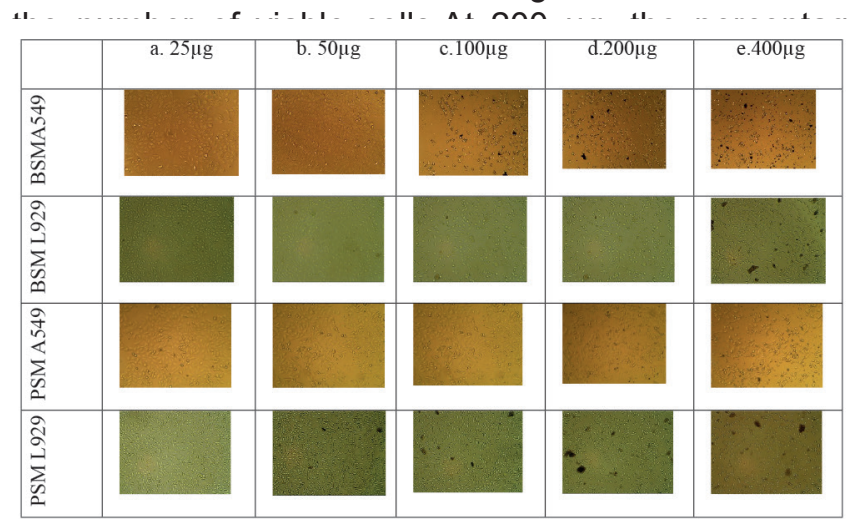

Plate1. Cytotoxic effect (Cell viability) of different concentrations of BSM and PSM on A549 and L929 cell lines 
cytotoxic activity of ethanolic and dichloromethane (DCM) extracts of Bacopa monnieri against MCF-7, and MDA-MB 231 cell line have been observed (20). The anti-cancer activity of the ethanolic extract of Bacopa monnieri against human breast cancer cell line (MDAMB-468) was observed in yet another study (21). The ethanol extract of Bacopa monnieri exhibited antiinflammatory activity against carrageenan-induced paw edema in mice and rats, an acute inflammatory model (22).

In the present study, the methanolic extracts of the stem of Plectrenthus ambionicus did not show significant cytotoxicity. From the results of the MTT assay, it is evident that BSM shows more cytotoxicity on human lung cancer cell lines than the PSM extract whereas the PSM extract exhibits increased antioxidant activity. The comparable cytotoxic potential of BSM on the A549 cancer cell line and its selective cytotoxicity sparing the normal cell line makes BSM extract a better choice to further explore its candidature as a potential natural anticancer drug.

\section{Conclusion}

Plectranthus ambionicus and Bacopa monnieri are herbs used extensively in traditional medicine. Evaluation of their potential as cancer therapeutic agents revealed that the methanolic stem extract of Bacopa monnieri has the required property. The plant may serve as a source of bioactives and metabolites which could be precursors for potent anti-cancer drugs.

\section{Acknowledgements}

The authors are thankful to the management of Kristu Jayanti College, Autonomous, Bengaluru for providing the facilities for the research work, M/s Stellixar Biotech, Bengaluru for the cytotoxicity assay and CSIRCECRI, Karaikudi for FTIR analysis

\section{References}

1. Khare, R.S; Banerjee,S; Kundu, K.K. (2011). Coleus aromaticusBenth. A nutritive medicinal plant of potential therapeutic value. Int. J. Pharma. Bio. Sci., 2:488-500.

2. Kumaran,A and Karunakaran, R. J. (2006). Antioxidant and free radical scavenging activity of an aqueous extract of Coleus aromaticus, Food Chemistry, vol. 97, no. 1, pp. 109-114.

3. Gurgel, A. P. A. D; Da Silva, J. G. A; Grangeiro, R. S. (2009). Antibacterial effects of Plectranthus amboinicus (Lour.) spreng (Lamiaceae) in methicillin resistant Staphylococcus aureus (MRSA). Latin American Journal of Pharmacy, vol. 28, no. 3, pp. 460-464.

4. Bhatt, P and Negi, P. S. (2012). Antioxidant and antibacterial activities of Indian borage (Plectranthus amboinicus) leaf extracts. Food and Nutrition Sciences, vol. 3, no. 3, pp. 146-152.

5. Annapurani, S and Priya, R. (1999). Antimutagenic, antitumorogenic, and antigenotoxic effects of polyphenol extracts of selected medicinal plants. Indian Journal of Nutrition and Dietetics, vol. 36 , no. 10 , pp. 431-435.

6. Arumugam, G; Swamy, M.K; Sinniah, U.R. (2016). Plectranthus amboinicus (Lour.) Spreng: Botanical, Phytochemical, Pharmacological and Nutritional Significance. Molecules. Mar 30;21(4):369. doi: 10.3390/molecules21040369. PMID: 27043511; PMCID: PMC6274163.

7. Praveena, B; Gilbert Stanley Joseph; Negi, P.S and Mandyam Chakravarthy Varadaraj. (2013). Chemical Composition and Nutraceutical Potential of Indian Borage (Plectranthus amboinicus) Stem Extract. Journal of Chemistry Volume 2013, Article ID 320329, 7 pages http://dx.doi. org/10.1155/2013/320329.

8. Gurgel, A.P; Da Silva, J.G; Grangiero, A.R; Oliveira, D.C; Lima, M.P; Silva, A.C; Oliveira A.G; Souza, I.A.(2009). In vivo study of the anti-inflammatory and antitumor of leaves from Plectranthusamboinicus (Lour.) Spreng (Lamiaceae) J. Ethnopharmacol. 125:361-363. doi: 10.1016/j.jep.2009.07.006.

9. Ramalakshmi, P; Subramanian, N; Saravanan, R; Mohanakrishnan, H; Muthu, M.(2014) Anticancer effect of Coleus amboinicus (Karpooravalli) on human lung cancer cell line (A549) Int. J. Dev. Res.;4:2442-2449.

10. Russo, A and Borrelli, F. (2005). Bacopa monniera, a reputed nootropic plant: an overview. Phytomedicine, vol. 12, no. 4, pp. 305-317.

11. Prabhakar, S; Saraf, M. K; Pandhi, P and Anand, A. (2008). Bacopa monniera exerts antiamnesic effect on diazepam-induced anterograde amnesia in mice. Psychopharmacology, vol. 200, no. 1, pp. 27-37.

12. Harsahay, M; Hemant, K. P; Pankaj, P; Mahesh, C. A and Zakwan, A. (2012). Evaluation of antioxidant activity of two important memory enhancing medicinal plants Baccopa monnieri and Centella asiatica. Indian Journal of Pharmacology, vol. 44, no. 1, pp. 114-117.

13. Khan, R; Krishnakumar, A and Paulose, C. S. (2008). Decreased glutamate receptor binding 
and NMDA R1 gene expression in hippocampus of pilocarpine-induced epileptic rats: neuroprotective role of Bacopa monnieri extract. Epilepsy and Behavior, vol. 12, no. 1, pp. 54-60.

14. Gohil, K. J. and Patel, J. J. (2010). A review on Bacopa monniera: current research and future prospects. International Journal of Green Pharmacy, vol. 4, no. 1, pp. 1-9, 2010.

15. Viji, V; Shobha, B; Kavitha, S. K; Ratheesh, M; Kripa, K and Helen, A. (2010). Betulinic acid isolated from Bacopa monniera (L.) Wettst suppresses lipopolysaccharide stimulated interleukin-6 production through modulation of nuclear factor- $k \mathrm{~B}$ in peripheral blood mononuclear cells. International Immunopharmacology, vol. 10, no. 8, pp. 843-849.

16. Viji, V; Kavitha, S. K and Helen, A. (2010). Bacopa monniera (L.) Wettst inhibits type II collageninduced arthritis in rats. Phytotherapy Research, vol. 24, no. 9, pp. 1377-1383.

17. Devishree, R.A; Kumar, S; Jain, A.R. (2017). Short term effect of Bacopa monnieri on memory- A brief review. J. Pharm. Res. 11, 1447-1450.)

18. Ashitha, G; Manjusha; Krupa Mary Jacob; Charles Lekhya Priya; Kokati, V. B. R. (2013). Phytochrmical Composition and Antioxidant Activities of Various Stem Extracts of Bacopa monnierin Linn. Research J. Pharm. And Tech. 6(9): page 1073-1078.
19. Mallick, M.N; Akhtar, M.S; Najm, M.Z; Tamboli, E.T; Ahmad, S and Husain, S.A. (2015). Evaluation of the anticancer potential of Bacopa monnieri against MCF-7 and MDA-MB 231 cell line. J Pharm Bioallied Sci; 7(4): 325-328.

20. Patil, A; Vadera, K; Patil, D; Phatak, A.; Juvekar A and Chandra, N. (2014). In-vitro anticancer activity and phytochemical analysis of Bacopa monnieri (L.) Wettst. Int J Pharm Sci Res: 5(10): 4432-38

21. Channa, S; Dar, A; Anjum, S; Yaqoob, M; Atta-Ur-Rahman. (2006) Anti-inflammatory activity of Bacopa monniera in rodents. J Ethnopharmacol. ;104:286-9

22. Alley, M.C; Gerlier, D; Thomasset, N. (1986) J. Immunol. Methods 94: 57-63, Harborne JB.Phytochemical Method. Chapman and Hall, 1976 New York, 1-288.

23. Mosmann, T. (1983). Rapid colorimetric assay for cellular growth and survival: application to proliferation and cytotoxicity assays. J Immunol Methods.; 65: 55-63.

24. MTT Cell Proliferation Assay Instruction Guide ATCC, VA, USA www.atcc.org

25. https://www.intechopen.com/books/ phytochemicals-source-of-antioxidants-androle-in-disease-prevention/introductory-chapterphytochemicals-and-disease-prevention 